\title{
Graft tendon slippage with metallic and bioabsorbable interference screws under cyclic load: a biomechanical study in a porcine model
}

\author{
Ari Digiácomo Ocampo Moré, André Luiz Almeida Pizzolatti, Eduardo Alberto Fancello, \\ Gean Vitor Salmoria, Carlos Rodrigo de Mello Roesler*
}

\begin{abstract}
Introduction: The rupture of the anterior cruciate ligament (ACL) is the most common type of knee injury. Reconstructive surgery is the 'gold standard' treatment. During the immediate post-operative period, the fixation of the graft is entirely dependent on the ability of the grafted implant to be secured inside the bone tunnel under the cyclical loads associated with daily tasks. Poor fixation can lead to graft slippage, thus impairing the healing and integration of the graft. The aim of this study was to evaluate the biomechanical performance of tendon graft fixation devices with metallic and bioabsorbable interference screws. Methods: Twenty ACL reconstructions were carried out in porcine tibias using deep flexor tendons to fix $9 \times 20 \mathrm{~mm}$ metallic $(n=10)$ and PLLA 70/30 bioabsorbable screws $(n=10)$. To verify the ability of a construct to resist immediate postoperative (PO) rehabilitation protocols for immediate load bearing, a cyclic loading test was applied with $50-250 \mathrm{~N}$ of tensile force at $1 \mathrm{~Hz}$ for 1000 cycles, and the displacement was measured at 10, 50, 100, 500 and 1000 load cycles to quantify the slippage of the graft during the test. After the cyclic loading test, a singlecycle load-to-failure test was applied. Results: The slippage of the graft using metallic screws did not differ $(\mathrm{P}=0.616)$ from that observed when using bioabsorbable screws. Conclusion: The results obtained in this experiment indicate that metallic screws may promote a similar amount of graft slippage during low cyclic loading as bioabsorbable screws. Additionally, there was no difference in the biomechanical performance of these two types of screws during high failure loads.
\end{abstract}

Keywords: Biomechanics, ACL reconstruction, Interference screw.

\section{Introduction}

The rupture of the anterior cruciate ligament (ACL) is the most common type of knee injury. Reconstructive surgery is the 'gold standard' treatment. This procedure requires special care during the postoperative period because the fixation of the graft at this stage is strongly dependent on the implant performance. Poor fixation may lead to graft slippage and tension loss, impairing the healing of the graft and the process of integration into the bone tunnel (Rodeo et al., 1993). Postoperative slippage at the fixation sites, including graft elongation and reduced graft construct stiffness, contributes to increasing joint laxity and recurrent instability (Bartz et al., 2007; Cuppone and Seedhom 2001; Daniel et al., 1985; Lopez et al., 2013). Clinically significant laxity occurs in $10-30 \%$ of knees within the 4 postoperative months (Hapa and Barber 2009; Roos et al., 2004). Graft tension loss during implantation and postoperative cyclical loading accounts for $17 \%$ of the cases of ACL reconstruction laxity (Ekdahl et al., 2008; Grover et al., 2005; Tyler et al., 1999; Woo et al., 2006) or fixation failures (Brand et al., 2000; Fu et al., 1999; Giurea et al., 1999). Thus, the early postoperative period following the reconstruction of the ACL is a critical time in relation to the success of the surgery (Becker et al., 2001; Brown et al., 1996).

Different implant technologies are available for fixing the graft inside the bone tunnel during the postoperative period. Since Kurosaka et al. (1987) reported their results, interference screws have been the preferred option of many surgeons for the fixation of the graft on the tibial side. The functionality of interference screws is dependent on their ability to act as a compression-loaded wedge to secure the ACL substitute graft within the bone tunnel, providing graft fixation (Figure 1).

Currently, two types of interference screw technologies are used: metallic and bioabsorbable. Metallic screws are used because of their strength, longevity and biocompatibility (Barber et al., 2000). Although they offer reliable performance, a drawback is the difficulty associated with remotion in revision surgeries (Almazan et al., 2006; Matthews and Soffer, 1989). The issue may lead to bone loss and the need for a bone graft to create the bone tunnel (Beevers, 2003). Bioabsorbable screws eliminate the need for 
remotion when revision surgery is required and do not interfere with MRI images (Kaeding et al., 2005). However, this type of screw is prone to breaking during surgery. The material may induce an exacerbated inflammatory response (Ghalayini and Banks, 2008; Shafer and Simonian, 2002). The migration of the screw in the joint space has also been occasionally reported (Baums et al., 2006). Given the advantages and drawbacks of each type of screw, no clear best option is evident. Few studies on this subject have been published, despite the recognized importance of ACL fixation.

The goal of this study was to evaluate the biomechanical performance of bone-implant constructs using metallic and bioabsorbable interference screws. The focus was to evaluate graft slippage inside the bone tunnel during cyclical loading and the strength of each fixation.

\section{Methods}

Twenty freshly frozen porcine legs of Landrace specimens were used in the experiments. They were stored at $-20{ }^{\circ} \mathrm{C}$ and thawed 12 hours before the test. This method allowed for a harvesting of the soft tissue. Each tibia was dissected and the deep flexor tendon of approximately $8 \mathrm{~mm}$ diameter was extracted for use as a graft. The use of the autograft instead of an artificial graft was preferred to mimic clinical practice. These grafts were then fixed to the tibia by ten bioabsorbable interference screws, PLLA 70/30 9×20 mm (Linvatec ${ }^{\circledR}$, Largo, Florida - USA), and ten metallic interference screws, $9 \times 20$ mm (Hexagon ${ }^{\circledR}$, Campinas, São Paulo - Brazil) (Figure 2). The fixation procedure followed the same clinical protocol established for ACL reconstruction in human knees. This procedure was performed by a trained orthopedic surgeon. In this fixation method, a $9 \mathrm{~mm}$ bone tunnel was drilled and an $8 \mathrm{~mm}$ graft was inserted. This procedure created a $1 \mathrm{~mm}$ gap between the graft and the tunnel bone wall. An outside-in screw insertion technique was performed. The screw was implanted with the help of a Kirschner wire to avoid divergence.

Immediately after the graft fixation, each tibia was clamped to a custom device with bone cement (PMMA) and screws. This device was then placed in the testing machine and aligned along the tunnel axis and loading direction. Therefore, the test was conducted in a worst case scenario. The free end of the graft was fixed in the load cell leaving a gage length of $30 \mathrm{~mm}$ to mimic the human intra articular ACL length (Figure 3). Each specimen was then submitted to cyclic and monotonic testing.

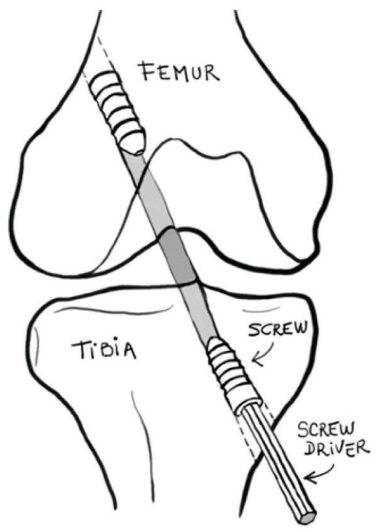

Figure 1. Interference screws in reconstructive surgery of ACL.

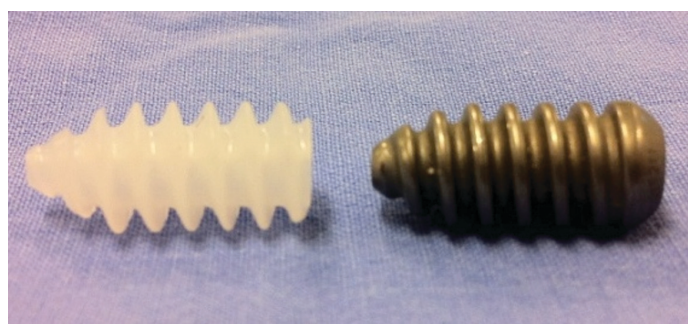

Figure 2. Bioabsorbable screw (on left; Linvatec ${ }^{\circledR}$, Florida, USA) and metallic screw (on right; Hexagon ${ }^{\circledR}$, São Paulo, Brazil).

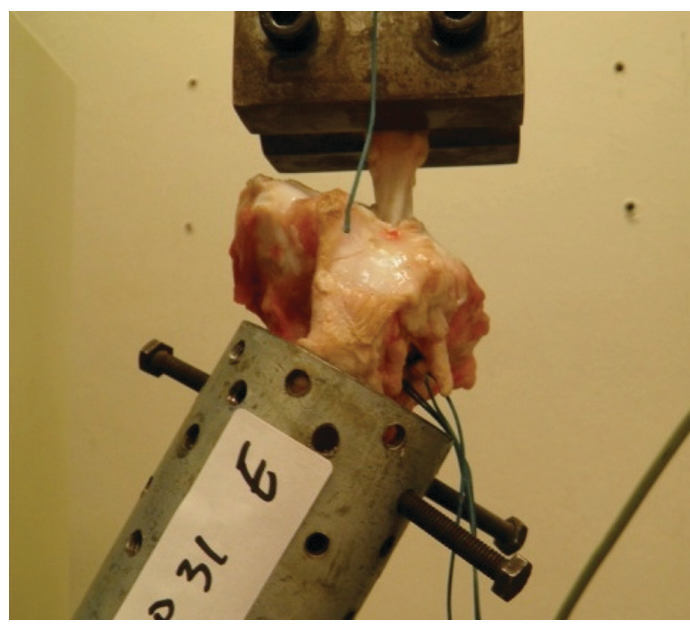

Figure 3. Method of tibia fixation for cyclic-loading and single-cyclic load-to-failure tests.

The cyclic test started with a preconditioning static tensile load of $50 \mathrm{~N}$ for $2 \mathrm{~min}$ followed by $1000 \mathrm{load}$ cycles at $1 \mathrm{~Hz}$ between $50 \mathrm{~N}$ and $250 \mathrm{~N}$. The slippage of the graft-fixation device interface was measured indirectly through the graft lengthening after 10, 50, 100, 500 and 1000 load cycles. This measurement represented the combined effect of the fixation device slippage and tendon stretch. This procedure was sufficiently accurate for the purposes of this study in accordance with clinical practice (Fabbriciani et al., 
2005; Kousa et al., 2003; Roos et al., 2004). Failure during cyclical loading was assumed to occur in cases in which a complete slippage of the fixation device was observed. The specimens that did not fail were submitted to a single-cycle load-to-failure test at a displacement rate of $50 \mathrm{~mm} / \mathrm{min}$ after the static preconditioning load. The values for the ultimate failure load (UFL), yield point load (YL), displacement at UFL, displacement at YL, linear stiffness and energy were obtained from the load-displacement curves (200 Hz sampling rate). The force $\mathrm{x}$ displacement curves were used to calculate these to examine the mechanical behavior of the whole bone-graft-implant system. The specimens were kept moistened by spraying with physiological solution $(0.9 \% \mathrm{NaCl})$.

Two way ANOVA was performed to evaluate the influence of the interference screw on the laxity during the cyclic tests. To analyze the effect of screw type on the UFL, YL, displacement at UFL, displacement at YL, linear stiffness, and energy, one-way ANOVA was performed. The significance probability level was set at 0.05 .

\section{Results}

Three fixation devices for each type of screw (metallic and bioabsorbable) failed during the cyclical-loading test. Consequently, these results were excluded from the statistical analysis. Figure 4 shows the displacement obtained for each fixation method. The slippage of each screw model indicated no significant differences in relation to the mechanical behavior $(\mathrm{F}=0.254 ; \mathrm{P}=0.616)$. In addition, no significant differences were observed between the metallic and bioabsorbable screws in terms of the

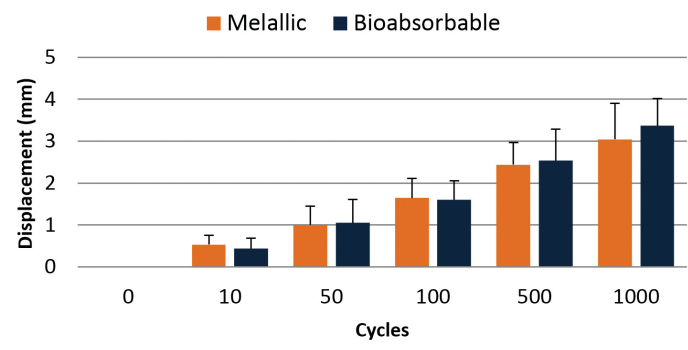

Figure 4. Fixation displacement during cyclical loading test.
UFL, YL, displacement at UFL, displacement at YL, linear stiffness and energy (Table 1).

\section{Discussion}

The method used for the fixation of an ACL graft must ensure that it is (1) secure enough to resist slippage under cyclic loading during the first 1 to 2 months after reconstruction, (2) stiff enough to restore the load-displacement response of the knee to normal, and (3) strong enough to avoid failure. Any fixation device with poor structural properties in slippage, stiffness or strength has the potential to compromise the clinical outcome.

The aim of this study was to evaluate the biomechanical performance of the tendon graft fixation device using two different implants. Special attention was given to the behavior under cyclic loading. Despite differences in the raw material (metallic and bioabsorbable) and the thread design of the two types of tested screws, the results showed that they displayed similar performances in relation to graft slippage. After 1000 load cycles, the fixation displacement results for the metallic and bioabsorbable screws were not significantly different: $3.28 \pm 0.55$ and $3.77 \pm 0.97$, respectively.

Magen et al. (1999) was the first to use graft-end displacement as a measure of the construct slippage. However, the methodological differences between their study and that reported herein hinder any direct comparisons of the results.

Kousa et al. (2003) performed a biomechanical study on several graft fixation techniques, including interference screws. The ACL reconstructions were performed by grafting quadrupled human semitendinosusgracilis tendons into porcine tibias. In the cyclical testing the constructs were loaded for 1500 cycles at 50 to $200 \mathrm{~N}$ at a frequency of $0.5 \mathrm{~Hz}$. The displacement after 1000 cycles of load was approximately $3.8 \mathrm{~mm}$ for the bioabsorbable BioScrew screws (Linvatec, Inc.) and $5.3 \mathrm{~mm}$ for the metallic Soft Silk screws (Acufex Microsurgical, Inc.). Their reported values obtained were consistent with those reported herein.

The fixation strength is related to the UFL values and must be sufficient to support the loading applied during daily tasks and accelerated rehabilitation

Table 1. Averages and standard deviations of single-cycle load-to-failure test.

\begin{tabular}{lccc}
\hline & Metallic screw $(\mathbf{n = 7})$ & Bioabsorbable screw $(\mathbf{n = 7})$ & P \\
\hline Ultimate Failure Load $(\mathrm{N})$ & $628.41 \pm 234.93$ & $607.11 \pm 97.49$ & 0.83 \\
Yield Point Load $(\mathrm{N})$ & $501.85 \pm 82.28$ & $509.98 \pm 94.03$ & 0.87 \\
Displacement at UFL $(\mathrm{mm})$ & $5.52 \pm 3.06$ & $5.40 \pm 1.74$ & 0.92 \\
Displacement at YL $(\mathrm{mm})$ & $3.76 \pm 1.43$ & $4.17 \pm 2.12$ & 0.68 \\
Linear Stiffness $(\mathrm{N} / \mathrm{mm})$ & $141.63 \pm 30.28$ & $138.97 \pm 39.82$ & 0.89 \\
Elastic Strain Energy $(\mathrm{J})$ & $2.30 \pm 2.64$ & $1.89 \pm 0.72$ & 0.64 \\
\hline
\end{tabular}


programs. Morrison (1970) reported $169 \mathrm{~N}$ as the ACL force during normal level walking. Noyes et al. (1984) reported that the maximum force on the graft fixation device occurs while descending stairs and is estimated to be approximately $445 \mathrm{~N}$. A load of $250 \mathrm{~N}$ was applied in our cyclic loading protocol. Previous studies have shown that ligament loads of this magnitude can be generated during quadriceps muscle contraction at full knee extension (Rupp et al., 1999). Considering that our study represents a worst case scenario, with loads applied to the graft in a direction corresponding to the axis of the tibial tunnel, the value of $250 \mathrm{~N}$ seemed to be a reasonable selection for the force that the graft should be able to repeatedly withstand during in vitro testing.

In the study reported herein, $30 \%$ of the metallic and $30 \%$ of the bioabsorbable screws failed by slippage during the cyclic testing with a maximum load of $250 \mathrm{~N}$. Nevertheless, all constructs were considered to be secure enough for their intended use. Our study represents a worst case scenario with loads applied to the graft in a direction corresponding to the axis of the tibia tunnel. This differs from the clinical situation in which an anterior displacement of the tibia causes graft loading at various degrees of knee flexion.

The single-cycle load-to-failure test performed with the specimens that survived the cyclic loading showed that the ultimate failure load was not significantly different between the two types of screws $(607.11 \pm 97.49 \mathrm{~N}$ and $628.41 \pm 234.93 \mathrm{~N}$ for the bioabsorbable and metallic screws, respectively). The UFL was above $390 \mathrm{~N}$ for all tested graft fixation devices, and all constructs were considered to be sufficiently secure for their intended use. The forces applied in an ACL graft tended to be lower than $390 \mathrm{~N}$ in the early postoperative period (Frank and Jackson, 1997). During this time, the reconstructed knees are restricted from vigorous use because of pain.

Weiler et al. (1998) performed comparisons using flexor tendons as grafts and observed different behaviors between metallic and bioabsorbable screws. The UFL for the bioabsorbable screw $(507 \mathrm{~N})$ was significantly higher than that for the metallic screw $(419$ N). Kousa et al. (2003) did not report UFL values for the constructs after cyclic loading. For the YL, a significant difference between BioScrew $(567 \pm 156 \mathrm{~N})$ and SoftSilk (423 $\pm 75 \mathrm{~N})$ was not found.

Another requirement for a successful ACL replacement is the stiffness of the fixation device, i.e., to reinstate the knee stability and restore the normal limits of anterior translation. Unsuitable stiffness results in recurrent knee laxity and may be a determining factor in the development of premature osteoarthrosis after ACL reconstruction. It has been proposed that achieving normal knee kinematics at the time of reconstruction may be more dependent on matching the stiffness of the replacement ligament to that of the native ACL than on matching the ultimate strength (Ishibashi et al., 1997). In our single-cycle load-to-failure test, the linear stiffness of the bioabsorbable screw $(138.97 \pm 39.82 \mathrm{~N} / \mathrm{mm})$ was not significantly different than that of the metallic screw $(141.63 \pm 30.28 \mathrm{~N} / \mathrm{mm})$. This could indicate the need for higher pre-tension to restore normal laxity when using these screws. The stiffness of the tested graft fixation devices was lower than that of the original ACL (182 N/mm (Noyes et al., 1984), $242 \mathrm{~N} /$ $\mathrm{mm}$ (Woo et al., 1992), $303 \mathrm{~N} / \mathrm{mm}$ (Rowden et al., 1997)). Weiler et al. (1998) performed comparisons with the flexor tendon as a graft and found different behaviors for metallic and bioabsorbable screws. The linear stiffness of the bioabsorbable screw $(57.9 \mathrm{~N} /$ $\mathrm{mm}$ ) was significantly higher than that of the metallic screw $(39.7 \mathrm{~N} / \mathrm{mm})$. In a study by Kousa et al. (2003), a significant difference in the values for the linear stiffness of BioScrew $(125 \pm 23 \mathrm{~N} / \mathrm{mm})$ and SoftSilk $(120 \pm 18 \mathrm{~N} / \mathrm{mm})$ was not found. Our results were consistent with those of Kousa et al. (2003).

The expected dependence of the graft fixation biomechanics on the thread designs generally differs for polymeric and metallic screws. In our study, the bioabsorbable screw has an asymmetric thread profile, while the metallic screw has a symmetric profile. These types of screws also differ in relation to the depth (d), pitch (p) and volume between two fillet threads (see Figure 5). These differences imply a distinct fixation performance, which was not observed in the tests. Thus, it is clear that many other mechanical and tribological issues play important roles at the interfaces, precluding the proposal of simple explanations for different fixation behaviors.

The study reported herein was conducted using animal tissue; however, porcine bone does not have the same mineral density as young human bone. Nevertheless, the methodology followed by this study allows for sample homogeneity and is considered a useful

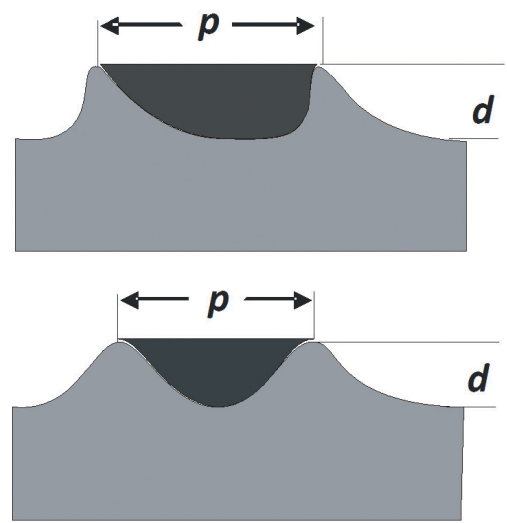

Figure 5. Relationship between thread depth (d) and pitch (p) and bone volume allocated between two fillet threads. 
model for ACL reconstruction studies (Nakano et al., 2000). Additionally, in the study reported herein, the response during the immediate postoperative period was investigated, before the healing of the graft in the bony tunnel. Despite these limitations, our results corroborate with those obtained in other similar studies (Almazan et al., 2006; Anderson, 2004).

Overall, the obtained results indicate that both types of interference screws promote similar biomechanical performances during low cyclic loading and high failure loads. Further research is required to determine the clinical relevance of these findings.

\section{Acknowledgements}

The authors would like to thank PRONEX-FAPESC, FAPESC, FINEP and CNPq for financial support.

\section{References}

Almazán A, Miguel A, Odor A, Ibarra JC. Intraoperative incidents and complications in primary arthroscopic anterior cruciate ligament reconstruction. Arthroscopy. 2006; 22(11):1211-7. http://dx.doi.org/10.1016/j.arthro.2006.06.019. PMid:17084299

Anderson AF. Transepiphyseal replacement of the anterior cruciate ligament using quadruple hamstring grafts in skeletally immature patients. The Journal of Bone and Joint Surgery. American Volume. 2004; 86-A(Pt 2, Suppl 1):201-9. PMid: 15466760

Barber FA, Elrod BF, McGuire DA, Paulos LE. Bioscrew fixation of patellar tendon autografts. Biomaterials. 2000; 21(24):2623-9. http://dx.doi.org/10.1016/S01429612(00)00130-7. PMid:11071612

Bartz RL, Mossoni K, Tyber J, Tokish J, Gall K, Siparsky PN. A biomechanical comparison of initial fixation strength of 3 different methods of anterior cruciate ligament soft tissue graft tibial fixation: resistance to monotonic and cyclic loading. The American Journal of Sports Medicine. 2007; 35(6):949-54. http://dx.doi.org/10.1177/0363546507301881. PMid:17435059

Baums MH, Zelle BA, Schultz W, Ernstberger T, Klinger HM. Intraarticular migration of a broken biodegradable interference screw after anterior cruciate ligament reconstruction. Knee Surgery, Sports Traumatology, Arthroscopy: Official Journal of the ESSKA. 2006; 14(9):865-8. http://dx.doi.org/10.1007/ s00167-006-0049-2. PMid:16479410

Becker R, Voigt D, Stärke C, Heymann M, Wilson GA, Nebelung W. Biomechanical properties of quadruple tendon and patellar tendon femoral fixation techniques. Knee Surgery, Sports Traumatology, Arthroscopy: Official Journal of the ESSKA. 2001; 9(6):337-42. http://dx.doi. org/10.1007/s001670100223. PMid:11734869

Beevers DJ. Metal vs bioabsorbable interference screws: initial fixation. Proceedings of the Institution of Mechanical Engineers. Part H, Journal of Engineering in Medicine. 2003; 217(1):59-75. http://dx.doi.org/10.1243/095441103762597746. PMid:12578220
Brand J Jr, Weiler A, Caborn DNM, Brown CH, Johnson DL. Graft fixation in cruciate ligament reconstruction. American Journal of Sports Medicine. 2000; 28(5):761-74. PMid:11032238

Brown GA, Peña F, Grøntvedt T, Labadie D, Engebretsen L. Fixation strength of interference screw fixation in bovine, young human, and elderly human cadaver knees: influence of insertion torque, tunnel-bone block gap, and interference. Knee Surgery, Sports Traumatology, Arthroscopy: Official Journal of the ESSKA. 1996; 3(4):238-44. http://dx.doi. org/10.1007/BF01466626. PMid:8739721

Cuppone M, Seedhom BB. Effect of implant lengthening and mode of fixation on knee laxity after ACL reconstruction with an artificial ligament: a cadaveric study. Journal of Orthopaedic Science. 2001; 6(3):253-61. http://dx.doi. org/10.1007/s007760100044. PMid:11484120

Daniel DM, Malcom LL, Losse G, Stone ML, Sachs R, Burks R. Instrumented measurement of anterior laxity of the knee. The Journal of Bone and Joint Surgery. American Volume. 1985; 67(5):720-6. PMid:3997924.

Ekdahl M, Wang JH-C, Ronga M, Fu FH. Graft healing in anterior cruciate ligament reconstruction. Knee Surgery, Sports Traumatology, Arthroscopy: Official Journal of the ESSKA. 2008; 16(10):935-47. http://dx.doi.org/10.1007/ s00167-008-0584-0. PMid:18633596

Fabbriciani C, Mulas PD, Ziranu F, Deriu L, Zarelli D, Milano G. Mechanical analysis of fixation methods for anterior cruciate ligament reconstruction with hamstring tendon graft. An experimental study in sheep knees. The Knee. 2005; 12(2):135-8. http://dx.doi.org/10.1016/j. knee.2004.05.001. PMid:15749449

Frank CB, Jackson DW. The science of reconstruction of the anterior cruciate ligament. The Journal of Bone and Joint Surgery. American Volume. 1997; 79(10):1556-76. PMid:9378743

Fu FH, Bennett CH, Lattermann C, Ma CB. Current trends in anterior cruciate ligament reconstruction. Part 1: Biology and biomechanics of reconstruction. The American Journal of Sports Medicine. 1999; 27(6):821-30. PMid:10569374.

Ghalayini SR, Banks AJ. Re: Bioabsorbabale interference screws used in anterior cruciate ligament reconstruction: potential effects of postoperative infection. The Surgeon: Journal of the Royal Colleges of Surgeons of Edinburgh and Ireland. 2008; 6(1):63. http://dx.doi.org/10.1016/S1479666X(08)80102-3. PMid:18318092

Giurea M, Zorilla P, Amis AA, Aichroth P. Comparative pull-out and cyclic-loading strength tests of anchorage of hamstring tendon grafts in anterior cruciate ligament reconstruction. The American Journal of Sports Medicine. 1999; 27(5):621-5. PMid:10496580.

Grover DM, Howell SM, Hull ML. Early tension loss in an anterior cruciate ligament graft. A cadaver study of four tibial fixation devices. The Journal of Bone and Joint Surgery. American Volume. 2005; 87(2):381-90. http:// dx.doi.org/10.2106/JBJS.C.01527. PMid:15687163

Hapa O, Barber FA. ACL fixation devices. Sports Medicine and Arthroscopy Review. 2009; 17(4):217-23. http://dx.doi. org/10.1097/JSA.0b013e3181bf668c. PMid:19910779 
Ishibashi Y, Rudy TW, Livesay GA, Stone JD, Fu FH, Woo SL-Y. The effect of anterior cruciate ligament graft fixation site at the tibia on knee stability: evaluation using a robotic testing system. Arthroscopy. 1997; 13(2):177-82. http:// dx.doi.org/10.1016/S0749-8063(97)90152-3. PMid:9127075

Kaeding C, Farr J, Kavanaugh T, Pedroza A. A prospective randomized comparison of bioabsorbable and titanium anterior cruciate ligament interference screws. Arthroscopy. 2005; 21(2):147-51. http://dx.doi.org/10.1016/j.arthro.2004.09.012. PMid:15689862

Kousa P, Järvinen TL, Vihavainen M, Kannus P, Järvinen M. The fixation strength of six hamstring tendon graft fixation devices in anterior cruciate ligament reconstruction. Part I: femoral site. The American Journal of Sports Medicine. 2003; 31(2):174-81. PMid:12642249.

Kurosaka M, Yoshiya S, Andrish JT. A biomechanical comparison of different surgical techniques of graft fixation in anterior cruciate ligament reconstruction. The American Journal of Sports Medicine. 1987; 15(3):225-9. http:// dx.doi.org/10.1177/036354658701500306. PMid:3303979

Lopez MJ, Borne A, Monroe WT, Bommala P, Kelly L, Zhang N. Novel anterior cruciate ligament graft fixation device reduces slippage. Medical devices (Auckland, N.Z.). 2013; 6(1):59-68. http://dx.doi.org/10.2147/MDER.S43802. PMid:23717051

Magen HE, Howell SM, Hull ML. Structural properties of six tibial fixation methods for anterior cruciate ligament soft tissue grafts. The American Journal of Sports Medicine. 1999; 27(1):35-43. PMid:9934416.

Matthews LS, Soffer SR. Pitfalls in the use of interference screws for anterior cruciate ligament reconstruction: brief report. Arthroscopy. 1989; 5(3):225-6. http://dx.doi. org/10.1016/0749-8063(89)90177-1. PMid:2673257

Morrison JB. The mechanics of the knee joint in relation to normal walking. Journal of Biomechanics. 1970; 3(1):5161. http://dx.doi.org/10.1016/0021-9290(70)90050-3. PMid:5521530

Nakano H, Yasuda K, Tohyama H, Yamanaka M, Wada T, Kaneda K. Interference screw fixation of doubled flexor tendon graft in anterior cruciate ligament reconstruction biomechanical evaluation with cyclic elongation. Clinical Biomechanics (Bristol, Avon). 2000; 15(3):188-95. http:// dx.doi.org/10.1016/S0268-0033(99)00065-0. PMid:10656980

Noyes FR, Butler DL, Grood ES, Zernicke RF, Hefzy MS. Biomechanical analysis of human ligament grafts used in knee-ligament repairs and reconstructions. The Journal of
Bone and Joint Surgery. American Volume. 1984; 66(3):34452. PMid:6699049.

Rodeo SA, Arnoczky SP, Torzilli PA, Hidaka C, Warren RF. Tendon-healing in a bone tunnel. A biomechanical and histological study in the dog. The Journal of Bone and Joint Surgery. American Volume. 1993; 75(12):1795-803. PMid:8258550.

Roos PJ, Hull ML, Howell SM. Lengthening of double-looped tendon graft constructs in three regions after cyclic loading: a study using Roentgen stereophotogrammetric analysis. Journal of Orthopaedic Research: Official Publication of the Orthopaedic Research Society. 2004; 22(4):839-46. http:// dx.doi.org/10.1016/j.orthres.2003.11.002. PMid:15183443

Rowden NJ, Sher D, Rogers GJ, Schindhelm G. Anterior cruciate ligament graft fixation: Initial comparison of patellar tendon and semitendinosus autografts in young fresh cadavers. American Journal of Sport Medicine. 1997; 25:472-8. http://dx.doi.org/10.1177/036354659702500409.

Rupp S, Seil R, Schneider A, Kohn DM. Ligament graft initial fixation strength using biodegradable interference screws. Journal of Biomedical Materials Research. 1999; 48(1):70-4 http://dx.doi.org/10.1002/(SICI)1097-4636(1999)48:1<70::AIDJBM12>3.0.CO;2-P. PMid:10029152

Shafer BL, Simonian PT. Broken poly-L-lactic acid interference screw after ligament reconstruction. Arthroscopy. 2002; 18(7):E35. http://dx.doi.org/10.1053/jars.2002.32197. PMid:12209420

Tyler TF, McHugh MP, Gleim GW, Nicholas SJ. Association of KT-1000 measurements with clinical tests of knee stability 1 year following anterior cruciate ligament reconstruction. The Journal of Orthopaedic and Sports Physical Therapy. 1999; 29(9):540-5. http://dx.doi.org/10.2519/jospt.1999.29.9.540. PMid:10518296

Weiler A, Hoffmann RF, Stähelin AC, Bail HJ, Siepe CJ, Südkamp NP. Hamstring tendon fixation using interference screws: a biomechanical study in calf tibial bone. Arthroscopy. 1998; 14(1):29-37. http://dx.doi.org/10.1016/S07498063(98)70117-3. PMid:9486330

Woo SL, Livesay GA, Engle C. Biomechanics of the human anterior cruciate ligament. ACL structure and role in knee motion. Orthopaedic Review. 1992; 21(7):835-42. PMid:1501921.

Woo SLY, Wu C, Dede O, Vercillo F, Noorani S. Biomechanics and anterior cruciate ligament reconstruction. Journal of Orthopaedic Surgery and Research. 2006; 1(1):2. http:// dx.doi.org/10.1186/1749-799X-1-2. PMid:17150122

\title{
Authors
}

\author{
Ari Digiácomo Ocampo Moré1, André Luiz Almeida Pizzolatti', Eduardo Alberto Fancello ${ }^{1,2}$, Gean Vitor \\ Salmoria ${ }^{1,3}$, Carlos Rodrigo de Mello Roesler ${ }^{1,2 *}$ \\ ${ }^{1}$ Laboratório de Engenharia Biomecânica - LEBm, Hospital Universitário Polydoro Ernani de São Thiago, Universidade \\ Federal de Santa Catarina - UFSC, Rua Professora Maria Flora Pausewang, s/n, Trindade, CEP 88036-800, Florianópolis, \\ $\mathrm{SC}$, Brazil
}

${ }^{2}$ GRANTE, Departamento de Engenharia Mecânica, Universidade Federal de Santa Catarina - UFSC, Florianópolis, SC, Brazil.

${ }^{3}$ Laboratório CIMJECT, Departamento de Engenharia Mecânica, Universidade Federal de Santa Catarina - UFSC, Florianópolis, SC, Brazil. 